\title{
The expression of Hsa-miR-155-5p in plasma samples of breast cancer before and after chemotherapy
}

\author{
Meutia Srikandi Fitria ${ }^{1 *}$, Sofia Mubarika Haryana ${ }^{2}$, Sumadi Lukman Anwar ${ }^{3}$, \\ Teguh Aryandono ${ }^{2}$, Dewi Sahfitri Tanjung ${ }^{1}$, Aprilia Indra Kartika ${ }^{1}$, Risky Oktriani ${ }^{4}$, \\ Irianianiwati ${ }^{5}$, Dwi Nur Indah Sari ${ }^{6}$ \\ ${ }^{1}$ Graduate Program in Biotechnology, School of Postgraduate, Universitas \\ Gadjah Mada, Yogyakarta, ${ }^{2}$ Doctoral Program, Faculty of Medicine, Universitas \\ Gadjah Mada, Yogyakarta, ${ }^{3}$ Dr. Sardjito General Hospital, Yogyakarta, Indonesia, \\ ${ }^{4}$ Department of Biochemistry, Faculty of Medicine, Universitas Gadjah Mada, \\ Yogyakarta, ${ }^{5}$ Department of Patology Anatomi, Faculty of Medicine, Universitas \\ Gadjah Mada, Yogyakarta, ${ }^{6}$ Graduate Program in Biomedicine, Faculty of Medicine, \\ Universitas Gadjah Mada
}

DOI: http://dx.doi.org/10.19106/JMedScieSup0048042016018

\section{ABSTRACT}

Breast cancer has emerged as the most common cancer-related mortality among women worldwide. Therefore, early cancer detection using biomarkers such as microRNA is required. One of microRNAs that has an important role in breast cancer development is miR-155. Hsa-miR-155-5p is an oncomiR that is commonly dysregulated in breast cancer. This study aims to determine the expression of hsa-miR-155-5p in breast cancer patient's plasma before and after chemotherapy. We collected 64 samples from breast cancer patients admitted to Dr. Sardjito Hospital in Yogyakarta. RNA from plasma was extracted using RNA Isolation Kit miRCURY-Biofluid. cDNA synthesis was performed using cDNA Synthesis kit II and quantification of miR-155-5p using ExiLent SYBR Green master mix (Exiqon). qRT-PCR results were then analyzed with Livak's method and compared (before and after chemotherapy) to t-test. Expression of miR-155-5p in the breast cancer patients' plasma after chemotherapy was significantly increased (10.59 times) when compared to before chemotherapy ( $p=0.001)$. We concluded that there was upregulated expression of miR-155-5p after chemotherapy than before chemotherapy. There has not been a known, relevant pathway between hsa-miR155-5p and chemotherapy regimens nor its impact on resistance to chemotherapy.

Keywords: Breast cancer, plasma, hsa-miR-155-5p, oncomiR, chemotherapy. 